\title{
Prevalence and factors associated with over-the-counter use of antifungal agents in Mwanza City, Tanzania
}

MARTHA F. MUSHI ${ }^{*}$, BENEDICTOR MASEWA ${ }^{2}$, MARY JANDE², MARIAM M. MIRAMBO', STEPHEN E. MSHANA'. 'Department of Microbiology and Immunology, Weill Bugando School of Medicine, P. O. Box 1464, Mwanza, Tanzania

${ }^{2}$ Department of Clinical Pharmacology, Weill Bugando School of Medicine, P.O. Box 1464, Mwanza, Tanzania

\section{Abstract}

Background: Misuse of antifungal agents both in clinics and agriculture has been associated with the increased trend of antifungal resistance. In Tanzania, there is limited information regarding the magnitude of antifungal obtained over the counter. This study was therefore, conducted to determine the extent of over the counter (OTC) antifungal use and factors associated to it.

Methods: This was a cross-sectional study involving patients buying antifungal agents from community pharmacies between May and July 2015 in Mwanza city, Tanzania. Data were collected by the investigator using interview guided questionnaire.

Results: A total of 270 patients were enrolled and interviewed. The mean age was $30 \pm 12$ years. Majority of patients (59.6\%) were females. Of the 270 patients, $188(69.3 \%)$ had dermatophytes. A total of $150(55.6 \%, 95 \% \mathrm{Cl}$ 49.6-61) obtained antifungal OTC. Of 150 patients who received antifungal agents OTC, 64 (42.3\%) received more than one antifungal agents compared to only $9.2 \%(11 / 120)$ of those with prescription $(p<0.001)$. Clotrimazole was the commonly prescribed antifungal agent while fluconazole was mostly obtained OTC. On univariate analysis, increase in age was found to be associated with the tendency of obtaining antifungal agents over the counter ( $\mathrm{OR} \mathrm{1.03,95 \%} \mathrm{Cl} \mathrm{1.008-1.05,} \mathrm{P}<0.006$ ). Having skin fungal infections was the only predictor of obtaining antifungal agents OTC (OR $3.36,95 \% \mathrm{Cl} 2.34-4.81, \mathrm{P}<0.001)$.

Conclusion: In Mwanza City, patients receive multiple antifungal agents over the counter and the practice is significantly more for those with skin fungal infections. There is a need for the advocacy on appropriate use of antifungal agent to reduce the associated impact of resistance development.

Keywords: Over the counter, dispensing, antifungal agents, Tanzania

\section{Introduction}

Invasive life threatening fungal infections have dramatically increased in the past three decades (Hudson, 2001; Sundriyal et al., 2006). The increased of fungal infections has been linked to increase use of the broad spectrum antibiotics, anticancer therapy and increase in prevalence of immunocompromised infections such as acquired immune deficiency syndrome (AIDS) (White et al., 1998). The phenomenon of switching of some antifungal agents from only prescription to over-thecounter (OTC), has provided conducive environment to the misuse of the antifungal agents (Lipsky \& Waters, 1999). The misuse has been implicated in the rise of antifungal resistant strains as the result of selective pressure (Stephenson, 1997; Hudson, 2001). Nevertheless the trends of opportunistic fungal infections have been observed to increase in recent decades from 18\% (Mayanja et al., 1999, Matee et al., 2000) to above 60\% (Nweze \& Ogbonnaya, 2011; Kwamin et al., 2013; dos Santos Abrantes et al., 2014), which has resulted in the increase use of antifungal agents.

Over-the-counter drugs are the medicines that an individual can buy without a prescription. Most often, they include pain relievers, allergy medicine, or various types of heartburn relief medications. Generally, over-the-counter medicines are less potentially dangerous than prescription medicines. Self-medication, including the use of over-the-counter (OTC) medicines is a global

\footnotetext{
* Correspondence E-mail: mushimartha@gmail.com
} 
phenomenon of public health concern (Bennadi, 2013; Schmiedl et al., 2014). High levels of selfmedication practices with over-the-counter medicines and complementary and alternative medications have been reported in Australia, United States and Germany (Bradley \& Blenkinsopp, 1996; Eisenberg et al., 1998; Hanlon et al., 2001; Beitz et al., 2004; Goh et al., 2004; MacLennan et al., 2006). In a multi-centre study in six Latin American countries, a relatively high percentage of prescribed medicines were being dispensed without medical prescription and this was attributed to lack of access to medical care (DURG, 1997).

Over the counter medications has the advantage of reducing health care cost. However, in addition to the fact that OTC and self-medication are the potential contributors to human pathogen resistance to antimicrobials, the adverse consequences of such practices may result in greater probability of inappropriate, incorrect, or undue therapy, missed diagnosis, delays in appropriate treatment, adverse drug reactions and increased morbidity (Lipsky \& Water, 1999; Hersh et al., 2007; Bennadi, 2013; Schmiedl et al., 2014). Worldwide studies on OTC antifungal uses are limited (Lipsky et al., 2000; Sihvo et al., 2000; Schneider et al., 2013). In sub-Saharan Africa including Tanzania, there is inadequate data regarding the OTC practices (Truter \& Graz, 2014). According to the Tanzania national policy on prescription of medicine, antibiotic and antifungal are prescribed drugs (Mnyika \& Killewo, 1991). Therefore, this study was conducted to determine the magnitude of OTC and its associated factors among patients with fungal infections in Mwanza City, Tanzania.

\section{Materials and Methods}

\section{Study design}

This cross sectional study was conducted in Mwanza City in north-western Tanzania, from May to July 2015 and involved community pharmacies. A total of 27 randomly selected community pharmacies out of 57 were visited. In each pharmacy the first ten patients enquiring antifungal agents were recruited into the study. The study excluded all patients' relatives/friends who visited the pharmacy to purchase antifungal agents and patients below 18 years of age.

\section{Data collection}

Data were collected through face-to-face interview using a guided questionnaire. Then, each enrolled patient was privately interviewed to obtain demographic and necessary information's such as type of infections, prescription status, type of antifungal dispensed, number of antifungal dispensed and previous history of antifungal use. The diagnoses were obtained from the prescriptions. For patients without prescriptions the clinical pharmacist made the diagnosis; in case of the inconclusive diagnosis, a medical doctor was consulted.

\section{Ethical considerations}

Ethical clearance was granted by the joint Catholic University of Health and Allied Science/Bugando Medical Centre Research Ethics and Review Committee. Permission to conduct the study was sought from all community pharmacies administrations. All patients were requested to sign the written informed consent before recruitment. All patients' data were kept as confidential.

\section{Data analysis}

In this study patients were cauterized into those who obtained antifungal agents without prescription (OTC group) and those with prescriptions (prescriptions group). The data were entered and cleaned using Microsoft Excel software and analysed using STATA Version 11. Age as continuous variable was summarized using mean \pm standard deviations. Categorical variables were summarized in proportions. Step-wise logistic regression analysis was done to determine factors associated with habit of 
obtaining antifungal agents over the counter. A p-value of less than 0.05 was considered as statistically significant at the $95 \%$ confidence interval.

\section{Results}

\section{Patient demographic characteristics}

A total of 270 patients with fungal diseases were enrolled. The mean age of patients was $30 \pm 12$ years and females accounted for the majority of patients ( $n=161 ; 59.63 \%)$. Only 27 (10\%) patients had a history of previous antifungal use (Table 1).

Table 1: Demographic characteristics and history of antifungal use and prescription status

\begin{tabular}{|llll|}
\hline Variable & Response & Frequency & Percentage \\
\hline & Male & 109 & 40.4 \\
\hline Prior antifungal use & Female & 161 & 59.6 \\
\hline & No & 243 & 90.0 \\
\hline Prescription status & Yes & 27 & 10.0 \\
\hline & No & 150 & 55.6 \\
\hline
\end{tabular}

\section{Fungal diseases}

The commonest fungal diseases were dermatophytoses $188(69.63 \%)$. Tinea corporis $43 \%$ (81/188), tinea pedis $25 \%$ (47/188) and tinea capitis 16\% (30/188) were the common dermatophytes observed (Figure 1).

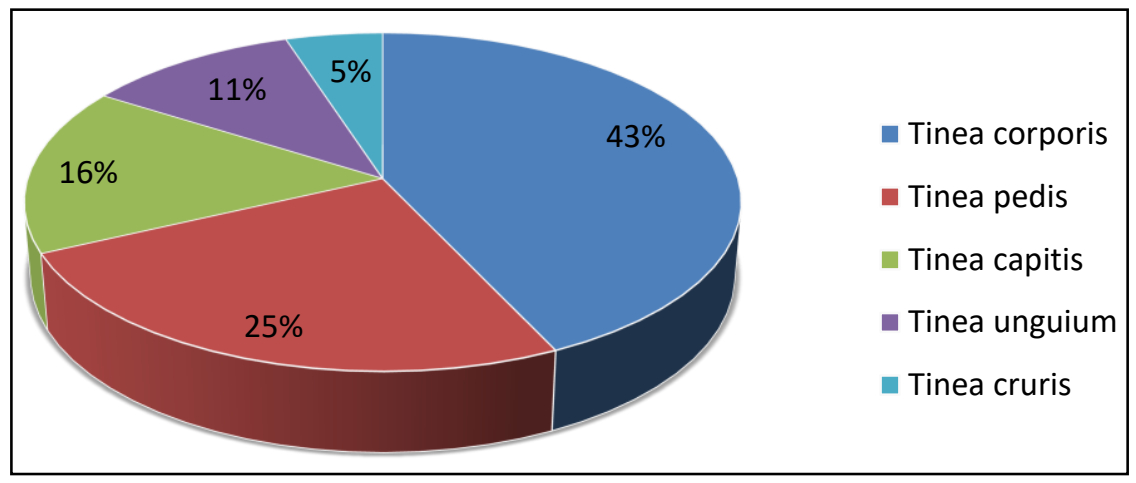

\section{Figure 1: Distribution of dermatophytes among patients}

Other fungal infections included vulvo-vaginal candidiasis 55 (20.37\%), oral candidiasis 19 (7.04\%) and systemic candidiasis 8 (2.96\%). In the current study systemic candidiasis was referred to the fungal infections involving blood stream and meninges. Most of the patients with dermatophytes either received fluconazole $46(24.47 \%)$ or the combination of fluconazole+clotrimazole $22(11.7 \%)$, while for vulvo-vaginal candidiasis most of the patients received clotrimazole 52 (94.55\%). All patients with oral candidiasis received nystatin (Table 2). Other antifungal drugs dispensed included Itraconazole capsules, Miconazole cream, Tioconazole, Salicylic acid and Benzoic acid. 
Table 2: Antifungal drugs dispensed in relation to diseases

\begin{tabular}{|llllllll|}
\hline Disease & Clot & Fluc/clot & Fluc & Nystatin & Griseofulvin & Ketoconazole & Others \\
\hline $\begin{array}{l}\text { Vulvo-vaginal } \\
\text { candidiasis (55) }\end{array}$ & $17(9.04 \%)$ & $22(11.7 \%)$ & $46(24.47 \%)$ & $0(0 \%)$ & $30(15.96 \%)$ & $24(12.77 \%)$ & $49(26.04 \%)$ \\
\hline Systemic candidiasis (8) & $0(0 \%)$ & $1(12.5 \%)$ & $3(37.5 \%)$ & $0(0 \%)$ & $0(0 \%)$ & $4(50 \%)$ & $0(0 \%)$ \\
\hline Oral candidiasis (19) & $0(0 \%)$ & $0(0 \%)$ & $0(0 \%)$ & $19(100 \%)$ & $0(0 \%)$ & $0(0 \%)$ & $0(0 \%)$ \\
\hline Total (270) & $69(25.56 \%)$ & $24(8.89 \%)$ & $49(18.15 \%)$ & $19(7.04 \%)$ & $31(11.48 \%)$ & $28(10.37 \%)$ & $50(18.52 \%)$ \\
\hline
\end{tabular}

Key: Clot= clotrimazole; Fluc/Clot= fluconazole+clotrimazole; Fluc= fluconazole

\section{Antifungal agents dispensed}

Of the 270 patients, the majority 150 (55.5\%) obtained antifungal agents over the counter (OTC) while $120(44.5 \%)$ obtained antifungal agents with prescription. The average number of antifungal dispensed per patients was 1.27 (270/343). The commonest class of antifungal dispensed was azoles, given either singly $148(54.8 \%)$, in combination of two azoles 69 (25.6\%) or azole with other type of antifungal agent 7 (2.6\%). Of 293 azoles dispensed, 197 (64\%) was given OTC. The commonest specific azole agent prescribed was clotrimazole whereas fluconazole was commonly obtained over the counter. Nystatin was most often prescribed than being obtained OTC (94.7\% vs. $5.3 \%, 95 \% \mathrm{Cl} 0.90-0.99, \mathrm{p}<0.001)$. Clotrimazole, fluconazole, ketoconazole and griseofulvin were commonly obtained OTC (Table 3). Out of 150 patients who received antifungal agents OTC, 64 (42.3\%) received more than one antifungal agents compared to only $9.2 \%(11 / 120)$ of those with prescription $(p<0.001)$.

Table 3: Common antifungal agents dispensed in relation to OTC and prescription status

\begin{tabular}{|lllll|}
\hline & Prescription & \multicolumn{2}{c|}{ Over the counter } \\
\hline Nystatin (19) & 18 & Percentage & Frequency & Percentage \\
\hline Clotrimazole (103) & 48 & 94.7 & 1 & 5.3 \\
\hline Fluconazole (104) & 36 & 46.6 & 55 & 55.3 \\
\hline Ketoconazole (60) & 13 & 34.6 & 68 & 65.4 \\
\hline Griseofulvin (31) & 4 & 21.7 & 47 & 78.3 \\
\hline Others (26) & 9 & 12.9 & 27 & 87.1 \\
\hline Total (270) & 120 & 34.6 & 17 & 65.3 \\
\hline
\end{tabular}

\section{Predictors of OTC}

The mean age of patients with prescription was $27.4 \pm 12.6$ years while the mean age of patients obtained antifungal agents OTC was $31.3 \pm 10.4$ years $p=0.006$. On univariate analysis, as the age increased by one year there was 3\% chance of obtaining antifungal over the counter (OR $1.03,95 \% \mathrm{Cl}$ 1.008-1.05, $\mathrm{P}<0.007)$. More males (65.4\%) than females (49\%) obtained antifungal OTC (OR $1.995 \% \mathrm{Cl}$ 1.17-3.1, $p=0.01$ ). All 27 patients with history of prior-use of antifungal agents were in the group of the OTC. Having skin fungal infections was the predictor of obtaining antifungal agents OTC (OR 3.36, 95\% $\mathrm{Cl}$ 2.34-4.81, $\mathrm{P}<0.001$ ) (Table 4). 
Table 4: Factors associated with over-the-counter (OTC) practices

\begin{tabular}{|lllllll|}
\hline & Rariable & Response & Univariate & & Multivariate \\
\hline Age & & OTC $(\%)$ & OR (95\%Cl) & P-value & OR (95\%Cl) & P-value \\
\hline Sex & Female (161) & $31 \pm 10$ & $1.03(1.01-1.05)$ & 0.006 & $1.01(0.98-1.04)$ & 0.384 \\
\hline & Male (109) & $79(49)$ & 1 & & & \\
\hline Diagnosis & None skin infections (82) & $14(17.1)$ & 1 & 0.01 & $0.94(0.51-1.7)$ & 0.869 \\
\hline & Skin infections (188) & $136(72.3)$ & $12.7(6.5-24.5)$ & $<0.001$ & $3.36(2.34-4.81)$ & $<0.001$ \\
\hline
\end{tabular}

\section{Discussion}

Availability of the antimicrobial agents OTC has been associated with the constant exposure of the pathogens to antimicrobial pressure which results to the increased antimicrobial resistance (Hudson, 2001). In the current study over half of the patients received antifungal agents OTC. The observed OTC practice is higher than that reported in a study in Jordan (Yousef et al., 2008). Self-medication has been described to be common in low-and-middle income countries (Greenhalgh, 1987; Van der Geest, 1987, 1990; Bezold, 1990) where health services are inadequate and poverty is common (Van der Geest \& Hardon, 1990). The common drawbacks of self-medication is the delay of making definitive diagnosis that can lead to delay in obtaining appropriate therapy, use of suboptimal therapy and misuse of the antifungal agents which include inappropriate combination of antifungal agents (Ferris et al., 2002; Francis et al., 2005). In the current study, four in every ten patients who received antifungal OTC had combination of topical and systemic antifungal agents. This is associated with the alter of the normal microbial flora and change the pattern of fungal infections (Hudson, 2001).

In the current study all patients with previous use of antifungal agents received drug OTC. The fact that most of the patients with prior history of antifungal use tended to obtain the subsequent doses OTC has also been reported elsewhere (Wood \& Brass, 2001). According to Ferris et al. (1996) only about one-third of patients with previous diagnosis of fungal infections could accurately diagnose a recurrent fungal infection; therefore, in about two third the subsequent treatment is inappropriate.

Azole agents are the major antifungal drugs used in the treatment of fungal infections worldwide. The emergence of azole resistant strains of fungi poses a great challenge in managing these fungal diseases (Bader et al., 2013; Mushi et al., 2016). In this study about two-thirds of the patients received azole antifungal agents OTC. The observed prevalence in our study is much higher than that reported previously by Mathema et al. (2001). The difference could be explained by the poor health seeking behaviour and lack of skin specialists in our setting. The use of topical antifungal agents is advocated to be under physician supervision to avoid suboptimal dosage and recurrence (Sutcliffe, 1998). In the current study having dermatophytes was found as predictor of obtaining antifungal agents OTC.

In conclusion, over the counter antifungal agent dispensing is high in Mwanza City and most of patients get combination antifungal therapy. Having skin fungal infections was found to predict the OTC practice. There is a need of re-enforcing the policy of antifungal prescription in Tanzania so as to reduce the consequence of antifungal misuse.

\section{Acknowledgements}

We would like to acknowledge the support obtained from all pharmacists and patients participated in this study. This study was supported by research grant from Catholic University of Health and Allied Sciences to MFM. 


\section{Conflict of interest}

Authors declare no competing interests.

\section{Author's contributions}

MFM, BM, MMM designed the study, BM and MJ collected the data, MFM and SEM analysed the data, MFM and SEM drafted the first manuscript, SEM critically reviewed the manuscript. All authors approved the final version of the manuscript.

\section{References}

Bader, O., Weig, M., Reichard, U., Lugert, R., Kuhns, M., Christner, M., Held, J., Peter, S., Schumacher, U. \& Buchheidt, D. (2013) Cyp51A-based mechanisms of Aspergillus fumigatus azole drug resistance present in clinical samples from Germany. Antimicrobial Agents and Chemotherapy 57: 3513-3517.

Beitz, R., Doren, M., Knopf, H. \& Melchert, H.U. (2004) Self-medication with over-the-counter (OTC) preparations in Germany. Bundesgesundheitsblatt Gesundheitsforschung Gesundheitsschutz 47: 1043-1050.

Bennadi, D. (2013) Self-medication: a current challenge. Journal of Basic and Clinical Pharmacy 5: 19-23.

Bezold, C. (1990) Future trends in self medication and selfcare. Journal of Social and Administrative Pharmacy 7:205-15.

Bradley, C. \& Blenkinsopp, A (1996) Over the counter drugs. The future for self medication. BMJ 312 (7034): 835-837.

Dos Santos Abrantes, P.M., McArthur, C.P. \& Africa, C.W.J. (2014) Multi-drug resistant oral Candida species isolated from HIV-positive patients in South Africa and Cameroon. Diagnostic Microbiology and Infectious Disease 79: 222-227.

DURG (1997) Multicenter study on self-medication and self-prescription in six Latin American countries. Drug Utilization Research Group, Latin America. Clinical Pharmacology and Therapeutics 61: 488-493

Eisenberg, D.M., Davis, R.B., Ettner, S.L., Appel, S., Wilkey, S., Van Rompay, M. \& Kessler, R.C. (1998) Trends in alternative medicine use in the United States, 1990-1997: results of a follow-up national survey. JAMA 280: 1569-1575.

Ferris, D.G., Dekle, C. \& Litaker, M.S. (1996) Women's use of over-the-counter antifungal medications for gynecologic symptoms. Journal of Family Practice 42: 595-601.

Ferris, D.G., Nyirjesy, P., Sobel, J.D., Soper, D., Pavletic, A. \& Litaker, M.S. (2002) Over-the-counter antifungal drug misuse associated with patient-diagnosed vulvovaginal candidiasis. Obstetrics \& Gynecology 99: 419-425.

Francis, S.-A., Barnett, N. \& Denham, M. (2005) Switching of prescription drugs to over-the-counter status. Drugs \& Aging 22: 361-370.

Goh, L.Y., Vitry, A.I., Semple, S.J., Esterman, A. \& Luszcz, M.A. (2009) Self-medication with over-thecounter drugs and complementary medications in South Australia's elderly population. BMC Complementary and Alternative Medicine 9:42

Greenhalgh, T. (1987) Drug prescription and self-medication in India: an exploratory survey. Social Science \& Medicine 25:307-18. 
Hanlon, J.T., Fillenbaum, G.G., Ruby, C.M., Gray, S. \& Bohannon, A. (2001) Epidemiology of over-thecounter drug use in community dwelling elderly: United States perspective. Drugs \& Aging 18: 123-131.

Hardon, A.P. (1987) The use of modem pharmaceuticals in a Filipino village: doctors' prescription and self medication. Social Science \& Medicine 25: 277-292.

Hersh, E.V., Pinto, A. \& Moore, P.A. (2007) Adverse drug interactions involving common prescription and over-the-counter analgesic agents. Clinical Therapeutics 29: 2477-2497.

Hudson, M.M. (2001) Antifungal resistance and over-the-counter availability in the UK: a current perspective. Journal of Antimicrobial Chemotherapy 48: 345-350.

Kwamin, F., Nartey, N.O., Codjoe, F.S. \& Newman, M.J. (2013) Distribution of Candida species among HIV-positive patients with oropharyngeal candidiasis in Accra, Ghana. Journal of Infection in Developing Countries 7: 41-45.

Lipsky, M.S. \& Waters, T. (1999) The "prescription-to-OTC switch" movement: its effects on antifungal vaginitis preparations. Archives of Family Medicine 8: 297.

Lipsky, M.S., Waters, T., Sharp, L.K. (2000) Impact of vaginal antifungal products on utilization of health care services: evidence from physician visits. Journal of American Board of Family Practice 13: 178-82

MacLennan, A.H., Myers, S.P., Taylor, A.W. (2006) The continuing use of complementary and alternative medicine in South Australia: costs and beliefs in 2004. Medical Journal of Australia 184: 27-31.

Matee, M., Scheutz, F. \& Moshy, J. (2000) Occurrence of oral lesions in relation to clinical and immunological status among HIV-infected adult Tanzanians. Oral Diseases 6: 106-111.

Mathema, B., Cross, E., Dun, E., Park, S., Bedell, J., Slade, B., Williams, M., Riley, L., Chaturvedi, V. \& Perlin, D.S. (2001) Prevalence of vaginal colonization by drug-resistant Candida species in college-age women with previous exposure to over-the-counter azole antifungals. Clinical Infectious Diseases 33: e23-e27.

Mayanja, B., Morgan, D., Ross, A. \& Whitworth, J. (1999) The burden of mucocutaneous conditions and the association with HIV-1 infection in a rural community in Uganda. Tropical Medicine \& International Health 4: 349-354.

Mnyika, K. \& Killewo, J. (1991) Irrational drug use in Tanzania. Health Policy and Planning 6: 180-184.

Mushi, M.F., Buname, G., Bader, O., Groß, U. \& Mshana, S.E. (2016) Aspergillus fumigatus carrying TR34/L98H resistance allele causing complicated suppurative otitis media in Tanzania: call for improved diagnosis of fungi in sub-Saharan Africa. BMC Infectious Diseases 16: 464.

Nweze, E.I. \& Ogbonnaya, U.L. (2011) Oral Candida isolates among HIV-infected subjects in Nigeria. Journal of Microbiology, Immunology and Infection 44: 172-177.

Schmiedl, S., Rottenkolber, M., Hasford, J., Rottenkolber, D., Farker, K., Drewelow, B., Hippius, M., Saljé, K. \& Thürmann, P. (2014) Self-medication with over-the-counter and prescribed drugs causing adverse-drug-reaction-related hospital admissions: results of a prospective, long-term multi-centre study. Drug Safety 37:225-235.

Schneider, C.R., Emery, L., Brostek, R., Clifford, R.M. (2013) Evaluation of the supply of antifungal medication for the treatment of vaginal thrush in the community pharmacy setting: $a$ randomized controlled trial. Pharmacy Practice 11: 132-137.

Sihvo, S., Ahone, R., Mikander, H. \& Hemmnki, E. (2000) Self-medication with vaginal antifungal drugs: physicians' experiences and women's utilization patterns. Family Practice 17 (2): 145-149.

Stephenson, J. (1997) Investigators seeking new ways to stem rising tide of resistant fungi. JAMA 277: 5-6.

Sundriyal, S., Sharma, R.K. \& Jain, R. (2006) Current advances in antifungal targets and drug development. Current Medicinal Chemistry 13: 1321-1335. 
Sutcliffe, A.G. (1998) Skin and nail fungi-almost beaten. British Journal of General Practice 48: 15501553.

Truter, I. \& Graz, M. (2014) Antifungal products dispensed by a group of community pharmacies in South Africa. South African Journal of Infectious Diseases 29: 75-79.

Van der Geest, S.K. (1987) Self-care and the informal sale of drugs in South Cameroon. Social Science \& Medicine 25:293-305.

Van der Geest, S.K. \& Hardon, A. (1990) Self-Medication in Developing Countries. Journal of Social and Administrative Pharmacy 7: 199-204.

White, T.C., Marr, K.A. \& Bowden, R.A. (1998) Clinical, cellular, and molecular factors that contribute to antifungal drug resistance. Clinical Microbiology Reviews 11: 382-402.

Wood, A.J. \& Brass, E.P. (2001) Changing the status of drugs from prescription to over-the-counter availability. New England Journal of Medicine 345: 810-816.

Yousef, A.-M.M., Al-bakri, A.G., Bustanji, Y. \& Wazaify, M. (2008) Self-medication patterns in Amman, Jordan. Pharmacy World \& Science 30: 24-30. 